\title{
Obituary: Johannes Boersma (1937-2004), a remarkable mathematician
}

\author{
H. K. Kuiken
}

Received: 31 October 2007 / Accepted: 31 October 2007 / Published online: 6 December 2007

(C) The Author(s) 2007

\section{Motivation}

This article is a tribute to Johannes Boersma, a mathematician who made an indelible impression upon all those who got to know him professionally. Yet, he never aimed to become a star among the stars. Indeed, only the relatively small group who knew him and interacted with him will be able to judge the extremely high level at which he was used to working. He deliberately kept himself out of the limelight. The joy of doing his kind of mathematics sufficed for him. He also seemed to derive great pleasure from helping others who got stuck in their research and showing them ways on how to solve their mathematical problems. I was one of those. Below are testimonials written by some of the colleagues, peers and others who either greatly benefited from collaborating with him or were awed by the way he handled his particular brand of mathematics.

The suggestion to write this tribute came from Professor Tony Rawlins of Brunel, a contributor to the special Wiener-Hopf issue (Vol. 59/4) for which this paper was originally planned. This is the kind of mathematics Boersma loved, along with the whole gamut of special functions and complex-function theory that many applied mathematicians now consider obsolete and superseded by numerics. How wrong they are, if only in view of the handling of singularities and the development of asymptotic constructs it affords! At a recent conference Prof. Rawlins spoke to me of his amazement that nothing of the kind seemed to have been done so far. Even so, the Mathematics Department in Eindhoven offered to organize a scientific conference on the occasion of Boersma's early retirement and he refused. Had he agreed, a book of symposium proceedings might have rendered this present paper superfluous. Although Boersma probably would have frowned upon the publication of a paper like this one, in which his person features so prominently, I believe it will serve a useful purpose. It may show what a life devoted to mathematics may look like, irrespective of career prospects and political in-fighting. Whatever career he may have had came naturally. It ended prematurely, since modern academic times and the emphasis it puts on funding had caught up with him.

I start with a section on testimonials written by some of Boersma's colleagues, both in The Netherlands and outside it, who knew him and his work well. They will emphasize different aspects of his activities and persona. Clearly, there will be some duplication of views, but this is understandable and serves to emphasize those points. In a later section I will present my own views, imperfect as these may be. The growth of the scientist will be sketched

H. K. Kuiken $(\bowtie)$

Department of Mathematics and Computer Science, Eindhoven University of Technology, P.O. Box 513, 5600 MB Eindhoven, The Netherlands

e-mail: H.K.Kuiken@tue.nl 
and his contributions and collaborations will be put in a, hopefully, proper perspective. With only 6 weeks, the time I had for this was fairly short. But then, the Internet and e-mail communication spares one weeks and weeks in dusty library vaults. This contribution will be completed by an incomplete list of Boersma's publications.

\section{Testimonials}

\subsection{Em. Professor D.S. Jones FRS, Department of Mathematics, University of Dundee, Scotland}

"I am delighted that you are devoting an issue of the journal to honour John Boersma. He thoroughly deserves this recognition of his magnificent achievements. He was an applied mathematician of the top rank who solved difficult problems with great skill and ingenuity. His analytical ability was superb and profound so that few of his generation could match his accomplishments. Yet he was a modest man and that modesty kept the international acknowledgement of his successes at a lower level than it should have been. Although his senior by many years, I never considered him my junior.

His prowess as a referee for papers submitted to journals was outstanding. His reports were unrivalled for the value of his comments. Often his report was as long as the original and no less informative. An author's theory had to be absolutely meticulous to earn John's approval. He must have pursued every argument in a submission to its logical conclusion, no matter how much time and effort were involved. A truly remarkable man whose contributions were highly appreciated by both authors and editors.

The early death of such a brilliant participant is a huge loss to mathematics. Not only has a superior intellect left us, but also the helping hand he held out so willingly to others can assist no longer. Let us admire him while we can."

\subsection{Professor Yahya Rahmat-Samii, Department of Electrical Engineering, UCLA, U.S.A.}

"Prof. John Boersma was an outstanding mathematician with a keen interest in applied diffraction problems in electromagnetics. I knew John since I was a student at the University of Illinois, Urbana-Champaign, U.S.A. He was a guest professor for a short duration at U. of Illinois and he and Prof. Andy Lee introduced me to the Uniform Asymptotic Theory (UAT) of diffraction. This was an elegant theory based on an ansatz which aimed at improving Keller's Geometrical Theory of Diffraction (GTD) near the shadow boundaries. The theory was developed by Lewis and Boersma in 1969. Subsequently, Prof. Mittra and I developed the Spectral Theory of Diffraction (STD) which unified the previously developed uniform theories.

Prof. Boersma became interested in STD, and we established technical collaborations resulting in a strong friendship. We worked on several technical papers together and I immensely benefited from his rigorous style in dealing with asymptotic evaluations of complex integrals. I also got to know John's wife and daughter. At one occasion, I stayed in their lovely house. I was also fortunate to see him at several conferences in Europe. The last time I saw John was at the URSI General Assembly held in Maastricht, The Netherlands in 2002.

Let me now elaborate a bit on some of the unique aspects of John's dedication to his profession. In the late seventies, I was an associate editor for the IEEE Antennas and Propagation Magazine's Book Review Column. In that capacity I regularly invited experts to review new books published in the areas of interest to the magazine's readership. At that time a new book was published about the Geometrical Theory of Diffraction and its applications. I requested that Prof. Boersma be a reviewer for the book. He accepted the request. In a matter of several months he completed his review. In my editorship era I never encountered such a detailed and thorough review of a book. John created a document of over 50 pages for a book of approximately 250 pages. By inspecting every mathematical aspect of the book, he was able to write an outstanding review. He wrote "Unfortunately the reviewer is rather unhappy about the quality of the book. The style of the book is poor and the analysis careless, incomplete or even wrong at various places...". He even took the time to go through the assignment problems in the book to make sure 
that I was certain it did provide invaluable feedback to the author. This is just one example demonstrating how much of a perfectionist he was in dealing with mathematical aspects of problems. I still use some of John's papers in my advanced graduate courses.

He was a superbly humble person with a creative mind and a no-nonsense approach in his mathematical development. I consider myself very fortunate having known such a gifted person and I will always cherish my friendship with such a giant."

\subsection{Professor A.D. Rawlins, Department of Mathematics, Brunel University, Uxbridge, UK}

"Joop Boersma was a first-rate analytical mathematician of the Dutch school who made substantial contributions in the rigorous theory of wave diffraction. He was a fantastic analyst and his contribution to rigorous diffraction theory is world-renowned. I knew Joop initially by his work, and then in my capacity as an editor for the Quarterly Journal of Mechanics and Applied Mathematics. His high standard of research work made him a natural referee for the many of the premier mathematics journals. For many years I corresponded with him on my own work and that of other authors. I last saw him at the 70th birthday celebrations of Professor Douglas Jones in Dundee. He always struck me as being a very modest, friendly, and open person.

It is difficult to convey the thoroughness that Joop exercised in his role of a referee of journal papers without seeing one of his beautifully hand-written reports. In many cases they ended up as nontrivial generalizations and extensions of the original manuscript. On a number of occasions the report submitted by Joop was so thorough and detailed that it was longer than the original paper submitted for publication! He put what looked like an enormous amount of effort into the refereeing process. And his reports where almost research papers in their own right. He was also a stickler for good English. I found it rather amusing that he as a Dutch academic was correcting English academics' language! He was without doubt the most conscientious, detailed and thorough referee I ever encountered during my thirteen years as an editor.

Joop was also well known as a problem solver in the problem pages of journals such as SIAM Review; these challenging problems were usually spin-offs from applied-mathematics research papers. Like all serious mathematicians he believed in problem solving as a way of sharpening one's analytical skills and developing new techniques to deal with future research problems.

His research papers are models for all serious researchers to consult for their power depth and clarity. I consider myself honoured in knowing and working with such a gifted person. The mathematical community will sorely miss him."

\subsection{Asst. Prof. Annemarie C.T. Aarts, Dept. Mathematics and Comp. Science, Eindhoven University of Technology, The Netherlands}

"Prof. Boersma was my PhD thesis supervisor during the years 1992-1997 at the Eindhoven University of Technology. Because I have been the only one who has taken a doctoral degree under his supervision, I have always felt honoured to have had the opportunity to do so. My PhD research was about instabilities occurring in the extrusion of polymer melts. Even though the subject was outside the field of electromagnetics that Prof. Boersma has extensively worked in, he was extremely dedicated in supervising my work. He provided me with the mathematical insights necessary for solving the mechanics problems I encountered. Thanks to his extensive mathematical knowledge of, for instance, complex functions, I was able to also prove aspects which I could only show numerically, or think of intuitively. By his thorough style of working, he showed me the necessity of delivering work of high standard and with mathematical precision, a quality I have benefited from ever since. He also taught me, by rewriting patiently all the poor sentences of my thesis, how to write and explain clearly in English. At the defense of the thesis he made a joke to the audience that 'they wouldn't be able to find an error in it anymore', something Prof. Boersma could assure since he had also checked every mathematical formula. 
As a third-year student in Mathematics, I got interested in the courses Prof. Boersma was teaching. These were courses such as Complex Function Theory, Applied Analysis and Partial Differential Equations which provided the interesting combination of mathematical theory applied to physics problems. Prof. Boersma was a gifted teacher, with a drive to explain in a sound way, by writing out the complete lecture on the blackboard. He was also known for his high demands. To pass for the Applied Analysis exams, for instance, one had to work on five problems for four full days, and we had to give up all other activities, resulting eventually in about 50 pages of answers. Looking back now, I see that he expected from the students the same amount of diligence that he always showed himself.

Towards the end of my $\mathrm{PhD}$ research, I got to know a little bit more of the man behind the mathematics. In some of the rare moments when we did not discuss mathematics, he proudly talked about his daughter studying medicine and his ever-supporting wife. When I met him later, during a 'Mathematics with Industry' symposium in 1999 (by then he had retired but was still working every day at the university on his kind of mathematics, and I had found a job in industry), our relation had changed from a professor-student one into one between two professionals, the one being an outstanding mathematician, and the other a pragmatist working on applications of mathematics. I still remember that already after one day Prof. Boersma solved the problem my group had been struggling with for quite some time.

Prof. Boersma was a devoted supervisor, with the ability to motivate and inspire. I regard myself privileged to have been taught by him, and I will always remember his patience and profoundness."

2.5 Em. Professor F.W. Sluijter, Department of Applied Physics, Eindhoven University of Technology, The Netherlands

\section{"History of a joint publication}

In 1981 I happened to be the thesis adviser of Cornelis A. van Duin [1]. Because the thesis was of a highly analytical nature, it was very relevant to seek a co-supervisor among the colleagues from the Mathematics Department. Who would better suit the purpose than Joop Boersma? As the nature of my work in classical theoretical physics often bordered on the competence of Joop, I had already the habit of sending my students to him to profit from his advanced courses in mathematical analysis. If they passed his exams, they really had learned something.

Joop never took the task of being a co-supervisor lightly. In his characteristic way he would go through the manuscript cover to cover. Every equation would be checked and, if proven to be correct, signed off like an oldfashioned schoolmaster would. Sometimes I even got the feeling he was replacing me altogether. But the quality of his remarks made me always repress my wounded pride. Apart from that, van Duin and I had the great advantage that in case someone thought he had found a mistake in the thesis, we could safely tell him the mistake was his. One of the chapters of the thesis especially drew his attention. It concerned the transverse magnetic mode in a planar waveguide with a graded index of the so-called symmetric Epstein type. For the transverse electric mode this problem leads to an eigenvalue problem that is solvable in terms of hypergeometric functions. For the TM mode the problem is more complicated, but could be reduced to an eigenvalue problem for a Fuchsian differential equation with four regular singular points, known as Heun's equation. The solution of this problem was far from trivial.

Based on the fact that we could interpret the resulting discrete spectrum as the guided wave modes of the waveguide, van Duin and I were convinced we had found the correct solution to the problem. However, Joop was not fully convinced.

We had decided to work out Chapter 4 of the thesis to a full-fledged article. About 5 months after the thesis defense the article seemed ready. The doubts in the mind of Joop remained. It was impossible to convince him of the strength of the physical arguments that were all in favor of the correctness of the solution found. The uncertainty lasted until the early spring of 1985, almost three and a half years later. Then Joop found the convincing lemma in the famous book by Dunford and Schwartz [2]. The article finally appeared in 1986 [3]. It was not easy to publish together with Joop. But the final outcome was more than worth the trouble." 
2.6 Professor David Wood, School of Engineering, University of Newcastle, Australia

My initial contact with John came after a student and I submitted a problem to SIAM Review, [4], which was published in one of the last issues that included a problem section. I only got one response: a long and very detailed solution from John Boersma, [5], which included a demonstration of my errors in formulating the problem! That salutary lesson set the tone of our subsequent collaboration. Based on his solution, John and I wrote two papers on the motion of helical vortices such as occur in the wakes of propellers, wind turbines, and hovering helicopters, $[6,7]$. John graciously, but firmly insisted that I be the lead author on the second paper, even though he did most of the work. The most interesting, and possibly unique, feature of doubly infinite helical vortices is that, at small values of the helix pitch, the self-induced velocity is due largely to the proximity of the nearby turns of the helix. For all other vortices that I know of, the self-induced velocity is set by the vortex curvature, through the "local induction" approximation, described for example, by Batchelor [8]. The unusual behaviour of helical vortices has some important implications for the analysis of wind-turbine performance that I am still working on. For example, it links the magnitude of the vortex pitch to the power produced. In deference to John, I should correct that last statement to "it links, to leading order,...".

John's mathematical analysis of the self-induced motion, along with my numerical solutions, were the main content of those two papers. Our solutions for the variation of self-induced velocity with pitch have become the standard for the field. I have two main memories of our collaboration which was all by correspondence-John and I did not meet face-to-face until after our work was done. The first is of the large number of long faxes I received. Some of these contained 30 or more pages of dense, hand-written mathematical analysis without a single correction or error. The second memory is of the only time I found a mistake in John's analysis: his asymptotic solution for small pitch agreed with my numerical solution to only six significant figures rather than the nine that our estimates of accuracy indicated. Somewhat tongue-in-cheek I e-mailed John to say that, as an engineer, six significant figures was fine but, of course, that was not good enough for him. He subsequently found and corrected the small error which re-established the nine-figure agreement.

I visited John around the time that our second paper was published. John, his wife Lolkje, and daughter Ykelien were great hosts and John even took us to a Dutch windmill during our weekend visit. During that visit, we discussed extending our work by considering the stability of helical vortex motion. John promised to bring his awesome mathematical knowledge to bear if I could formulate the problem succinctly. This I could never do satisfactorily and our collaboration ended. Subsequently, Okulov and Sorensen [9] published a beautiful analysis, but there is much yet to be done.

It was a joy and a privilege to collaborate with John. I was continuously amazed at his ability to produce long, detailed, and near-perfect analyses. Because that was something I could never do, I had to work hard to keep my own sense of worth. That challenge was for me in many ways the best thing that arose from our work."

\subsection{Professor Folkmar Bornemann, Technische Universität München, Germany}

"Even though John Boersma and I have never collaborated on a paper and, sadly in fact, never had the opportunity to meet each other personally, we have collaborated quite closely on many mathematical aspects of the book on the SIAM 100-Digit Challenge [10]. During this time I certainly came to admire his mathematical knowledge, taste, and accuracy.

The story of our collaboration, spread over about 100 e-mails from June 3, 2002, to September 13, 2004, goes as follows:

John and some of his friends were, like me, among the 20 winning teams of the 2002 SIAM 100-Digit Challenge set up by Nick Trefethen from Oxford University. Some of the contestants posted their solutions to the web; so did I. John had contacted me by e-mail to discuss some of its mathematics. In his first e-mail (June 3, 2002) he wrote:

Congratulations to ... you on winning a first prize in the SIAM 100-dollar, 100-digit Challenge. We also won a first prize: 'we' stands for a team consisting of J. Boersma, J.K.M. Jansen, F.H. Simons and F.W. Steutel, 
all retired mathematicians. ... In Problem 9 I like especially your solution in terms of a Meijer's $G$-function ... Meijer was one of my teachers at the University of Groningen 45 years ago, and I even published a paper on the $G$-function under his supervision. So I feel kind of ashamed that I did not think of such a solution.

Later, when the project of writing a book on the mathematics of this contest came up, I invited him to join in as a co-author. He answered (January 28, 2003):

Your eloquent plea has convinced me that it is worth while to publish a book on the SIAM contest problems. ... Although I would love to participate, I believe I better stay with my decision to not be an author of one or more chapters of the book. I have at least two reasons: I am a slow writer and I am a perfectionist who wants to study his subject in all detail. Thus it would take me a long time to write my chapter(s), and I do not want to put such a burden on my co-authors. Moreover, I am tired of trying to write perfect papers, and I do not want to worry myself while living in the Ruhestand.

Instead, he suggested to serve as a reviewer, 'willing to go through other people's texts, make comments, and suggest possible improvements.' This is what he actually did to us authors, unselfishly, detailed, timely, honest, full of knowledge and experience, but uncompromisingly. He became, in a way, a kind of invisible co-author. It is certainly a much better book than what we would have written without his energetic reviewing. The Acknowledgements of our book start with the sentence:

First, we owe a special debt of thanks to John Boersma, who looked over all the chapters with an expert eye and brought to our attention many places where the exposition or the mathematics could be improved.

The last e-mail of his that I received was on September 13, 2004, acknowledging that he had received his complimentary copy of our book from the press. After discussing some aspects of random walks on hypercubes (which was material in Chapter 6 that I had put in the book as a surprise and hidden thanks for him), he closed his e-mail with the sentences:

I guess this e-mail marks the end of a certain period. I hope we will stay in touch in the future. Please send me copies of your papers, notes, problems, etc.- -you know what subjects have my interest.

Sadly, John was not given the time for any more, he died exactly 11 weeks later. Personally, being almost 30 years younger than John, I can only say that I will treasure my correspondence with him. His modesty and his dedication to mathematics as a subject, and not just a career, serves as a personal example that has become rare in this time of competitive research with so many grant proposals full of selling phrases and void of substance.

I know that one of his ongoing projects was the reviewing of the chapter on Meijer's $G$-function for NIST's project 'Digital Library of Mathematical Functions'. It is tragic that he was not able to finish it. You may now understand why I have dedicated my short piece on explaining Mathematica's use of the G-function to John [11]."

Author's note: One of the authors of [10] has given a separate partial account of the SIAM contest [12]. In sadness over Boersma's death, Laurie dedicated the article to him.

\subsection{Em. Professor J.B. Keller, Stanford University and Courant Institute, U.S.A.}

Author's note: During the mid-sixties, Boersma spent 1 or 2 years at the Courant Institute in New York. Although he never published joint papers with J.B. Keller, Boersma's work at that time was strongly motivated by Keller's new ideas about geometrical optics and diffraction. Assuming that Keller must have taken note of Boersma's work at the time and before and after, I asked him for some details, not in the least because he is also an honorary editor of this journal. This, among other things, is what he wrote:

"Some years ago I wrote a paper about the singularities of solutions of the reduced wave equation at the tip of a plane angular sector, correcting and extending some published work of someone. John wrote to me that he had done very similar work, and sent me copies of an unpublished report, and perhaps also a paper. I replied 
thanking him, and apologizing for not knowing about his work. That was my only interaction with him since he left Courant, although I often saw references to his work."

Author's note: This was typical of Boersma. When he had completed an interesting piece of mathematics, he was happy to write a report about it and leave it at that, only to find out later that someone else had published it instead, albeit much later. I have seen more examples of this, but he did not seem to feel any pangs of regret: "it is good that someone else has taken the trouble to allow others to enjoy these results", he seemed to imply.

\subsection{Professor M.L. Glasser, Clarkson University, Potsdam (NY), U.S.A.}

"I was very affected when I learned of John Boersma's death. A few weeks before, he informed me of the unfavorable results of his recent medical examination, but thought the situation was being controlled and had returned to his usual activities. My direct contacts with John and his family were very few, limited to two visits to Nuenen when my wife and I traveled in Holland.

I began corresponding with John and his colleague Pieter de Doelder about problems in The SIAM Review, to which they were prolific contributors. Over the years John and I published five papers in 1983, 1991, 1999, 2000 and 2005. ${ }^{1}$ The last item was in press at the time of John's death and may have been his last publication. ${ }^{2}$

In each case, I sent John a note I had written and asked him to go over my rather amateurish treatment of an integral or summation that arose. In each case I would get back by return mail 10 or 20 pages of commentary in closely spaced precise handwriting on how the calculations could be carried out more efficiently, extended to provide more accuracy and, usually, interesting historical information. This formed the basis for a new and improved joint paper. I still preserve nearly 100 pages which have not yet been fully mined."

\subsection{Professor J. Molenaar, Wageningen University and Research Centre, Wageningen, The Netherlands}

"My first acquaintance with Joop Boersma was virtual, as I realized afterwards. Long ago, I applied for a PhD position at Eindhoven University of Technology (TU/e) and, at their request, sent the committee some reports on turbulence theory that originated from a project carried out during my military service. I was interviewed by some TU/e committee members, but not by Joop. For personal reasons, I decided to take another job. Months later I received my reports back and noticed that my derivations, which undoubtedly revealed the work of an unexperienced, starting scientist, had been revised with a lead-pencil in a very neat handwriting. Especially, the asymptotic analysis of an integral had been fully worked out in a few, efficient lines. The annotations were so to the point, that I recognized the fingerprint of a real expert. Apparently, a member of the selection committee had not been able to resist the temptation to improve my immature analyses.

Many years later I moved to TU/e after all and my first office there was next to Joop's. Initially he made the impression of being a stiff character, but this changed as soon as we got better acquainted. Joop turned out to be a very friendly person who liked to talk about a lot of things. It was at that time that I became aware that the annotations in my reports stemmed from no one else than Joop himself. In the course of time I found him to be a man of great integrity, who had not the slightest ambition to get involved in the internal politics of the faculty. We shared a number of aspects, e.g., the Calvinistic religion. Apart from mathematics, we also shared another hobby: playing the organ. We both had at home a so-called harmonium with pedals. This is a sort of substitute for a church organ, and in former days it used to be a standard ingredient of many a Calvinistic household. Once, when Joop and his wife were visiting our family, we all greatly enjoyed gathering around the harmonium, singing hymns accompanied by Joop. His turn for music was not widely known, but he was an enthusiastic organ player.

\footnotetext{
1 Author's note: see list of Boersma's publications.

2 Author's note: it was not.
} 


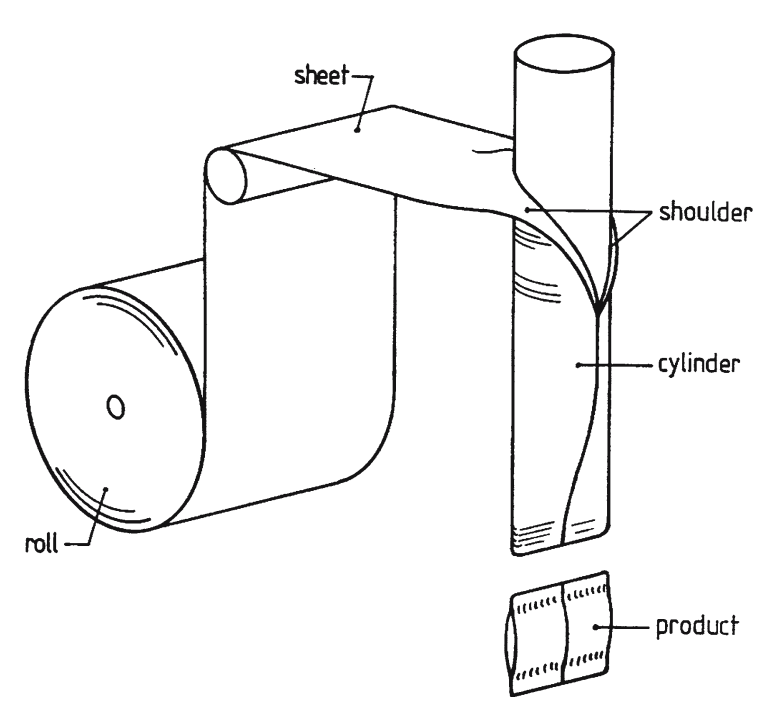

Fig. 1 Schematic drawing of the packaging machine

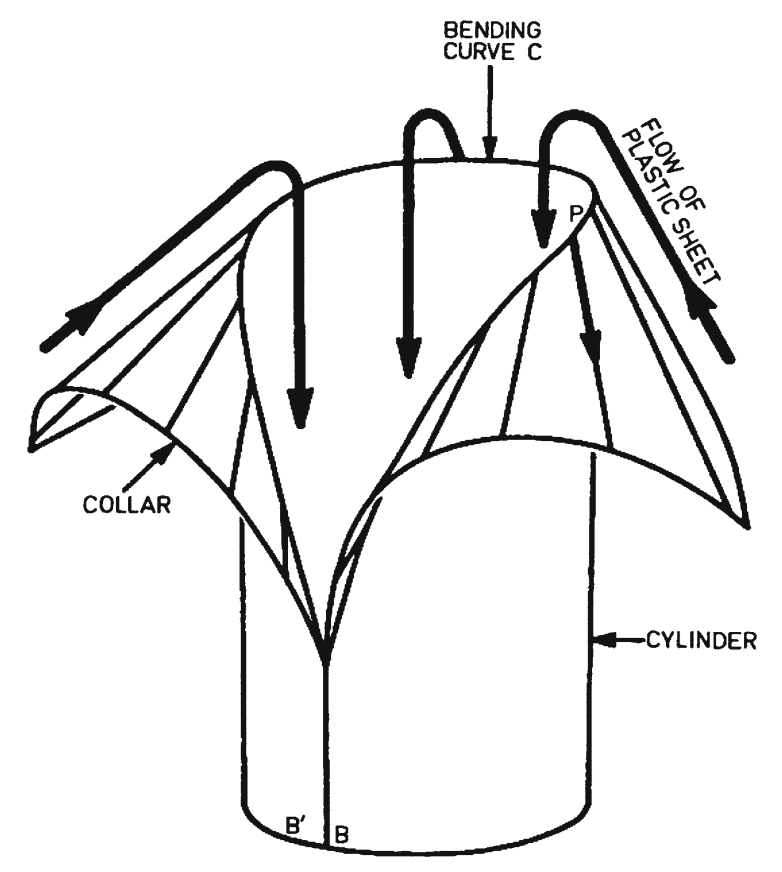

Fig. 2 Side-view of the 'shoulder' or 'collar'

Although we maintained a good personal contact, we did not cooperate scientifically until I came across a project for which I invoked his help. It stemmed from a company constructing packaging machines for all kinds of household stuff. The packaging material, paper or plastic sheet, enters the machine flat and unfolded. Then, it is folded such that it fits around a cylinder. The bag is formed by sealing it at the top, the bottom and the side. In fact, these geometrical matters can be explained only by means of a geometrical sketch (see Fig. 1).

To manage the transition from flat to cylindrical, the sheet slides over a metal surface, in packaging jargon referred to as 'shoulder' or 'collar' and shown in Fig. 2. The shoulder surface should be designed such that the sheet neither stretches nor tears upon passing it. From Joop I learned that in terms of differential geometry this condition leads to a so-called 'developable surface', i.e., a surface in 3D that is isomorphic with the plane. We studied the only paper ever published on the subject and Joop got enthusiastic for the topic. He decided to join me when visiting the company. We made an excursion through the factory and discussed the way shoulders were designed and manufactured in practice. Joop listened most of the time and asked only a few questions. We were told that the founding father of the company had figured out that shoulders could be constructed by carving a so-called 'bending curve' in a steal plate and folding the lower part around a cylinder. If the upper part of the plate is pushed backwards at the same time, it automatically assumes the shoulder form. As for the bending curve, he always took a parabola with equal height and baseline, and from practice he knew that this results in a top angle (the angle between shoulder and cylinder at the highest point) of $\pi / 3$. Back at the university, Joop rushed to the blackboard and started to work out our general theory for the special case of a parabolic bending curve. Improvising, but not making any error, he eventually concluded that such a parabola leads to a top angle of 59.132 degrees. We were astonished over this accurate agreement between the trial-and-error insight of the craftsman and our theory. Observing such a nice relationship between craftsmanship and mathematical modeling gave Joop great satisfaction. The shoulder problem led to nice discoveries and was a source of great pleasure for us both. It took many years before we published it, as Joop was extremely hesitant in writing his part of our paper [13]. I guess that the reason for the delay has to be attributed to the topic being somewhat exotic for him: the emphasis was not on the mathematics, but on the answer to an industrial problem. But anyway, I am sure that it is the only paper that I have been involved with that does not contain a single error, not even a typo, thanks to the microscopically precise editing work of Joop. 
Joop officially left the TU/e without any festivity, since he disliked to be the centre of interest, but he kept visiting the institute regularly. Then, one day, he talked to me point-blank about his health problems. Yet, his sudden passing away was a real blow. We miss a fine colleague and friend, who was blessed with a far-above-average talent for mathematics, but who always remained humble and helpful."

\section{Some details about his career as a mathematician}

Johannes Boersma was born in the village of Marrum in the very North of The Netherlands in the province of Friesland. His father was the headmaster of a nearby junior high school. His family and friends called him Joop, as we did as colleagues, but later on he preferred to be called John in his dealings with colleagues from abroad. In what follows I will simply use his family name to avoid confusion. The young Boersma revealed a precocious gift for learning. Having first tried his father's school, his parents sent him to a secondary school of higher rank, holding the middle between high school and college in the U.S.A. Normally pupils of such schools complete their secondary education when they are 18 . The young Boersma was still a child of 15 when his teachers had taught him all they could.

Since the province of Friesland had lost its only university in 1811 at the hands of Napoleon, he went to nearby University of Groningen and enrolled in the Department of Mathematics and Physics. He was still 15 at the time. Groningen had already made a name for itself as an institute specialised in the kind of mathematics that Boersma himself would excel in later on. The physicist/astronomer Jacobus Kapteyn (1851-1922), whom mathematicians know for the series named after him, gave rise to a dynasty of famous mathematicians/astronomers. The most well known of his students were Willem de Sitter (1872-1934) whose name is connected with a theoretical model for the universe and Jan Oort (1900-1992) who was considered by some to be the foremost astronomer of his time. Both were Frisians, but later moved on to Leiden University. Early on during his studies in Groningen, Boersma became greatly interested in the work of C.S. Meijer. Meijer has become renowned for the $G$-function and the transform that got his name. The $G$-function, in particular, has been a lifelong interest of Boersma's. At the time of his death he was working on a chapter devoted to that function for the NIST project regarding the Digital Library of Mathematical Functions. Still a student of only 20, Boersma won a prize for an investigation into certain properties of Meijer's $G$-function in 1958. In 1962 he published a paper based on that prize-winning study [14].

The man who would have the greatest influence on Boersma's development as a scientist was Christoffel J. Bouwkamp, who hailed from a small village close to the city of Groningen. Bouwkamp was Boersma's senior by 18 years. Bouwkamp had already earned himself an international reputation with his thesis, written in the Dutch language and published in 1941. His thesis supervisor, F. Zernike, would later be awarded the Nobel Prize in physics. Much later, the Editors of the IEEE Transactions on Antennas and Propagation asked him to provide an English translation. This was subsequently published in that journal [15]. It was the first of a series of papers published by that journal devoted to older, less accessible work that was recognized for its great archival value. In 1954 Bouwkamp had published a paper entitled Diffraction theory [16] that has been referenced no less that 407 times since 1960 until the present day. Bouwkamp clearly was one of the foremost diffraction theorists of his time.

In 1956 Boersma met Bouwkamp when he was allowed to spend some time at Philips Research Laboratories in Eindhoven, The Netherlands to get a few months in industry working on problems with a practical twist. It was only natural that Bouwkamp, the mathematician, should become his supervisor there. Bouwkamp, a boisterous man, is certain to have made a deep impression on young Boersma. In an obituary [17] that he wrote in collaboration with A.T. de Hoop, both men write that they consider themselves Bouwkamp's students, although they were not in the stricter sense of the word. Anyhow, Bouwkamp must have talked to Boersma with great enthusiasm about the field of diffraction theory and what interesting problems still lay ahead. Boersma wrote a doctoral thesis [18] entitled Boundary value problems in diffraction theory and lifting surface theory. The thesis also appeared as a journal publication [19]. The second part of the title may have been motivated by his thesis supervisor, A.I. van de Vooren who, in his time, was a well-known theoretical fluid mechanician. Van de Vooren was one of the founding fathers of the Journal of Engineering Mathematics. Earlier this year (2007) he passed away. 
It was diffraction theory that kept Boersma's attention going for a long time. Only much later would he return to fluid mechanics when he collaborated with D.H. Wood [6,7] in a study on helicopter and wind-turbine flows.

In 1967 Boersma was appointed full professor of mathematics at Eindhoven University of Technology which had been founded only a few years before. Bouwkamp had a part-time professorship there which he combined with his job at nearby Philips Research Laboratories. No doubt he had exercised his powers of conviction to effectuate this appointment of the 29-year-old Boersma. In his inaugural speech [20] Boersma set out his plans for the future.

During his stint at Courant, a few years earlier, Boersma got acquainted with J.B. Keller's work on new developments in Geometrical Diffraction Theory. This resulted in collaborative work with, among others, R.M. Lewis. The reader is asked to consult the list of Boersma's publications included at the end of this paper (see Appendix) for further information on this and other topics. Although I have no direct evidence of this, it is quite imaginable that Bouwkamp, who was then regarded a leader in the field, had a lot to do with Boersma's getting this highly desirable and effective postdoctoral position at Courant.

Reading through the testimonials of Sect. 2, one may get an impression of other interesting positions and collaborations of Boersma later on. However, I now turn to the counterpoint of his mathematical career, which was problem solving. This was something he really doted on. Again, it is possible that Bouwkamp had infected him with the virus at one time or another. When Bouwkamp was my boss at Philips Research Laboratories he would, for instance, sing the praise of a reduction method he had used to turn a 6-fold integral into a single integral, thus rendering it amenable to numerical treatment. Boersma would scan the problem sections of such journals as SIAM Review, Nieuw Archief voor Wiskunde and American Mathematical Monthly for problems that he liked. He would then bring to bear his almost endless knowledge of special functions, juggling in the complex plane or downright mathematical logic to solve the most outlandish problems. He particularly preferred problems that the poser had provided with a star, that is, for which no solution was known in a strict mathematical sense. These problems and his solutions for them were like ever so many beautiful melodies superposed on the main theme that was his rock-solid mathematical base tone.

I say counterpoint, since apart from the sheer joy that drove him, these problems gave him an opportunity to interact with others. Indeed, many of his later contacts with the mathematical world at large stemmed from corresponding with other enthusiasts wherever these might be active. The Professors Wood (Sect. 2.6) and Bornemann (Sect. 2.8) give interesting examples of this. A very fertile collaboration emerged when the Professors Boersma and Glasser got to know about each other's interests (see Sect. 2.9). Glasser may well have been the most prolific player of the SIAM problem section after Murray Klamkin and O.P. Lossers, ${ }^{3}$ so a crossing of paths was almost inevitable. Just to illustrate the sort of problems these two applied their minds to, I copy the abstract of their final paper [21], published in 2005, posthumously as far as Boersma was concerned:

The differentiation formula

$$
\left(1-\frac{\sqrt{z^{2}+a^{2}}}{z} \frac{\mathrm{d}}{\mathrm{d} z}\right)^{n}\left[z^{n-1 / 2} \mathrm{~K}_{n-1 / 2}(z)\right]=\left(z+\sqrt{z^{2}+a^{2}}\right)^{n} z^{-1 / 2} \mathrm{~K}_{1 / 2}(z)
$$

is derived, where $\mathrm{K}_{n-1 / 2}(z)$ is a modified spherical Bessel function and $a$ is an arbitrary constant.

Glasser admits this is not the most profound problem either he or Boersma had worked on, but it serves its purpose as an illustration.

It so happens that [21] will not be the final paper to which Boersma's name will be attached as an author. In a deliberate search on the internet I came across a preprint that will appear as a journal publication during 2008 [22]. It is a very fortuitous coincidence that this paper will be published in a journal that bears the name of one of the wonders of mathematics of the last century. Ramanujan, as appears from G.H. Hardy's account [23], regarded

\footnotetext{
${ }_{3}$ O.P. Lossers is a collective name, not a single person. In English the name would have read S. Olvers. It stands for a group of avid problem solvers of the Mathematics Department of Eindhoven University of Technology. Boersma was one of them. Whenever they tackled a problem that he was an expert on-and there were many of those-one can be certain that he took care of most of the solution process.
} 
mathematics as a source of pure enjoyment. He was used to formulating the most impossible problems and then derive their solutions in a way that amazed the likes of Hardy and many after him. John Zucker, one of the authors of [22] writes:

"I contacted John B. (as I always addressed him by e-mail—he called me John Z.) on the recommendation of another colleague of mine, Larry Glasser. I had found a representation of the Euler sums we were considering as integrals and I asked Larry if he knew anything about them. He told me to contact John B. whom he knew very well, and from then on a most fruitful co-operation occurred. Unfortunately I have lost the original e-mails but I think our contact began in the middle of 2002.

My impressions of John B. from our e-mail correspondence was that of a most courteous family man. His mathematics was meticulous, and his comments, criticisms and corrections of the first drafts of our paper were always precisely to the point and improved our presentation considerably. I attach a pdf copy of the paper [24] and would say that most of Sect. 3 and all of Appendix B was John's work.

I regret most sincerely that I never had the chance to meet John personally, a pleasure I have missed."

Again, this shows how Boersma liked to work with others: from a position of relative anonymity, seeking other modes of contact that were both effective and to the point.

Words such as modest and humble appear frequently in the testimonials on Boersma in Sect. 2. In Sect. 2.1 Professor Douglas Jones implies that Boersma would have succeeded in establishing himself more firmly, had he developed a more aggressive attitude towards publishing. The list of his publications that is appended to this paper is to all accounts and purposes quite substantial, but could have been far more extensive had he not devoted a lot of his time to work that earned him, at best, an acknowledgement in a paper or book. Also, there is much in what he has left that contains publishable material, but he felt, and I have heard him say this, that one should not burden the world with matter that the world is not waiting for to see the light of day. When I embarked on the task of writing this paper, I was handed a large box of manuscripts and notes that were mostly related to his problem-solving activities and consulting. A quick inspection of that box, and for all I know there may be more boxes like that, indicates that there is much that may be worked out into good papers. It may have all the appearances of a new Bateman project in the making.

An early sign of this reticence was shown when he published his first paper [25], a paper of only a single page. He shows how a recent method developed by C. Lanczos could be used to derive two approximation formulae that allow one to obtain nine-digit accuracy for Fresnel integrals. All he does on the single page is describe the two formulae and a table that he had obtained by means of the old valve computer ZEBRA. For the details of the derivation Boersma referred to a 14-page report [26] that I managed to dig up from the vaults of the Groningen math library. I daresay that most would not have even contemplated entrusting the mathematics of [26] to an internal report, but would have published it in the open literature instead of [25]. Yet the 1-page paper turned out to be one of Boersma's most successful publications. It has earned itself over 60 references.

The enormous energy that Boersma put in improving the work of others has already been pointed out earlier on in this paper (see, for instance, Sects. 2.2 and 2.7). As an E-i-C of this journal I can confirm what was said by Profs. Jones and Rawlins (Sects. 2.1 and 2.3). His referee reports were simply overwhelming in detail and perspicuity. But again he preferred to work in relative anonymity. When I invited him to join the Board of the Journal of Engineering Mathematics, he refused. He simply did not want to be compromised in that way.

I know of another example, similar to that of Prof. Rahmat-Samii's (see Sect. 2.2), where a book was improved greatly through his hard and dedicated work. This time he acted of his own volition. In his work he frequently referred to [27]. This is the kind of book that was most useful to him and he liked it a lot. However, on using it, he found it to be rife with inaccuracies. I do have a densely packed 15-page report in which Boersma points out all the inaccuracies he had found and corrections for them. He sent this to the authors of [27] who later produced a second improved edition as a Dover publication. In their preface they write "In regard to corrections, we would like to express a special debt of gratitude to John Boersma, whose careful reading and extensive list of corrections have provided the bulk of outside information for this edition." And indeed, this is all that Boersma got for a few months' 
work. The realisation that a book that he respected and liked was now closer to perfection was really all he needed. I have been told that his copy of Watson's Bessel Functions was absolutely full of annotations and corrections.

Creative scientists know that the subconscious and intuition are important in their research. Being handed a manuscript or paper in one's own field of expertise, one often sees at a glance when there is something wrong with it. One may not be able to pin-point the error straightaway, but the gut feeling is unmistakable. A colleague once gave me an extreme example of this in the case of Boersma. He was acting as a supervisor of a PhD student. When the first draft of the thesis had become available, he suggested that the student should discuss it with Boersma. "I can already tell you now what will happen", he said. "Boersma will begin by leafing through the thesis and stop at a page that has a lot of mathematics on it. A few seconds later he will point his finger somewhere and say: "That is wrong!"." The student replied: "This won't happen with my thesis. I have checked everything carefully. There are no errors left in it." But sure enough, it happened exactly as the colleague had predicted.

In spite of what was said in the previous paragraph, in his own work Boersma acted mostly as an inexorable deduction machine. He felt ill-at-ease when the strict deduction process had ground to a halt and methods based on physical insight had to be resorted to. In Sect. 2.5 Sluijter gives an interesting example of this. When Boersma applied techniques that belong to the realm of asymptotics, then this was always done in a strict mathematical sense, for instance as pursued in [27]. He knew that I liked problems that give rise to singular perturbation techniques, for instance matched asymptotic expansions. When applying such methods, particularly in the case of highly nonlinear problems, one frequently has to take recourse to downright physical arguments, which are often designated disparagingly as 'hand waving'. At one time or another Boersma confided to me that he had no feeling whatsoever for that sort of thing. Dr S.W. Rienstra, another colleague of mine at the Department of Mathematics in Eindhoven, who has a similar predilection for singular perturbations, heard the same from Boersma. We do not think that he rejected this methodology but simply felt that he lacked the talent for it or thought it beyond the scope of mathematics. He was a mathematician, not a physicist, albeit that many of the models he worked on came from physical contexts.

\section{Some personal notes}

Most of this account has been about Boersma and his mathematics. Only in some of the testimonials of Sect. 2 there is a smattering of personal details. Indeed, in his dealings with his colleagues he kept his personal affairs well-separated from his work. He was considered a reserved personality who hardly talked about his personal life. Hence his sudden death came as a shock to many.

Although he strictly kept all his appointments as a matter of course, there is a notable exception when his Frisian roots got the better of him. This was shortly after the $200-\mathrm{km}$, so-called 11 -cities race had been announced. This is a momentous skating event held in the province of Friesland on those rare occasions when the province's entire lake and canal system has frozen over, the ice being sufficiently thick to withstand the pressure of tens of thousands of participants. This was in the mid-eighties, the previous race having been held as far back as 1963 . The race is announced only a few days in advance, upon which thousands of enthusiasts and hopefuls converge on Friesland's capital city of Leeuwarden, or Ljouwert as they say in those parts. The entire race is televised from dawn to dusk and longer if need be. The heroics are great. On that very day—was it in 1986? - Boersma had to be present at an important departmental meeting. But he did not show up. He had decided to spend the day in front of his television set.

Another occasion when his Frisian background shone through clearly appears from an email correspondence with Professor Otto Ruehr of Michigan Technical University. The subject of the correspondence was problem 94-18* of the SIAM Review problem section. This was one of those 'starred' problems. On a personal note, Ruehr writes that, as a child, he and his family passed through Holland on their way from Hamburg to New York in the year 1939. In a return message Boersma writes-I omit some of the earlier pleasantries_: “....Your visit to Holland in 1939 is a long time ago-I was just over one year old then! At the end of this week, on May 5th, I plan to go to my native province of Friesland to attend the commemoration of the liberation in 1945. There will be a long train of allied army trucks and tanks going through the province, and I want to watch them at the same place where I stood 50 years ago." 
I do believe that Boersma's religious convictions partly explain the dedication he showed in his profession. Of course, a host of other influences that I know nothing about have also been at play here. Boersma was an observant Calvinist. Calvinism is a denomination within the Protestant faith, which itself is a division of Christianity. A central tenet within Calvinism is that one should not pride oneself in having certain talents, no matter how big these are. Having found a talent within oneself, one has the obligation to double (this is used metaphorically) it during one's lifetime. This explains both his humble disposition and the enormous energy that he expended as long as he was able to do this. I am not implying, of course, that everyone with a similar background and similarly talented will live the same sort of life. It is here that the other parameters, which will remain hidden to us, played their parts.

\section{Epilogue}

Summing up and speaking as Editor-in-Chief, I daresay that applied-mathematics publishing would be far superior to what it is now when all the authors and all the reviewers would maintain the same standards as Boersma did. But then, the non-perfect allows the superior to shine more clearly. This, perhaps, may serve as a consolation for those of us who lack the talents of someone like Boersma. It is always good for young and aspiring authors to read the works of some of the really great. I myself benefited a lot from reading some of James Lighthill's papers early on in my career. They were a real inspiration. I believe that many a young researcher will benefit equally from reading the best of Boersma. If they try to emulate his style and precision, they will benefit from that for the rest of their careers.

Acknowledgements I am grateful to all of those whose contributions have enriched this paper and whose names are mentioned in it. Special thanks are due to B.L.J. Braaksma and A.E.P. Veldman, both of the University of Groningen and J. de Graaf, S.W. Rienstra and A.A.F. van de Ven, all of Eindhoven University of Technology, for some pertinent details about Boersma that have found their way into this paper. I apologize to those that I perhaps should have asked to contribute, but forgot to involve. All I can do is plead ignorance.

Open Access This article is distributed under the terms of the Creative Commons Attribution Noncommercial License which permits any noncommercial use, distribution, and reproduction in any medium, provided the original author(s) and source are credited.

\section{Appendix, partial list of J. Boersma's publications}

Below is a partial list of J. Boersma's publications. In view of the short time available to collect the necessary data, it was impossible to mention all of Boersma's publications. Hence only those publications that appear in the Web of Science will be found below. The vast majority are journal publications. Only a few reports that he (co)authored when working abroad are mentioned. The many reports that he wrote or collaborated on in Eindhoven have not been listed, although the contents of many of these are good enough to deserve publication in the open literature. Clearly, the many solutions that he produced as an anonymous member of the O.P. Lossers group (there may well have been hundreds) will have to go unnoticed. The publications are listed in chronological order.

Boersma, J (1960 or 1961) Computation of Fresnel integrals. Math Comput 14:380

Boersma, J (1961) Mathematical theory of the two-body problem with one of the masses decreasing in time. Bull. Astron. Insts. Netherlands 15, nr. 505:291-301

Boersma, J (1961) Two formulas relating to elliptic integrals of the third kind. Math Comput 15:291-298

Boersma J, Kamminga, W (1961) Calculation of the volume of intersection of a sphere and a cylinder. Proc. Koninklijke Akad. Wetenschappen, Series A 64:496-507

Boersma, J (1962) On a function, which is a special case of Meijer's $G$-function. Compositio Mathematica 15:34-63

Boersma J (1962) On the computation of Lommel's functions in two variables. Math Comput 16:232-238

Boersma J (1964) Limit of sequence of real functions. Amer Math Monthly 71:331-332

Boersma, J (1964) Boundary value problems in diffraction theory and lifting surface theory. Compositio Mathematica 16:205-293 (This is also J. Boersma's Doctoral Dissertation.)

Boersma J (1965) Abel limit of nearly periodic sequences. Amer Math Monthly 72:326

Boersma J (1966) Electromagnetic diffraction by a unidirectionally conducting circular disk. SIAM J Appl Math 14:1471-1495 
Boersma J (1967) Uniform asymptotic solutions of discontinuous initial value problems for dispersive hyperbolic equations. Q Appl Math 25:31-44

Boersma J (1967) Buiging, een spel van licht en schaduw (In Dutch. English translation: Diffraction, a play of light and shadow). Inaugural speech. Eindhoven University of Technology, $19 \mathrm{pp}$

Ahluwalia DS, Lewis RM, Boersma J (1968) Uniform asymptotic theory of diffraction by a plane screen. SIAM J Appl Math 16:783-807

Carlitz L, Boersma J (1968) A double sum. SIAM Rev 10:117-119

Lewis RM, Boersma J (1969) Uniform asymptotic theory of edge diffraction. J Math Phys 10:2291-2305

Boersma J (1969) Expansions for Coulomb wave functions. Math Comput 23:51-59

Boersma J (1972) Electromagnetic diffraction by a circular disk between 2 different media, comments on a paper by D.L. Jain. Appl Sci Res 26:315-317

Boersma J (1974) Ray-optical analysis of reflection in an open-ended parallel-plane waveguide-II-TE case. Proc IEEE 62:1475-1481

Lee SW, Boersma J (1975) Ray-optical analysis of fields on shadow boundaries of two parallel plates. J Math Phys $16: 1746-1764$

Boersma J (1975) Analysis of Weinstein's diffraction function. Philips Res Repts 30:161-170, Suppl. I

Boersma J, Legrand P (1975) Iterative solution of a discrete axially symmetric potential problem. Proc. Koninklijke Akad. Wetenschappen, Series A 78:1-12

Boersma J (1975) Diffraction by two parallel half-planes. QJMAM 28:405-425

Boersma J (1975) Ray-optical analysis of reflection in an open-ended parallel-plane waveguide.1. TM case. SIAM J Appl Math 29:164-195

Boersma J (1976) Limit of an integral. SIAM Rev 18:770-772

Boersma J, Lee SW (1977) High-frequency diffraction of a line-source field by a half-plane-Solutions by ray techniques. IEEE Trans Anten Propag 25:171-179

Boersma J (1977) A simple solution of Sommerfeld's half-plane diffraction problem. J Appl Sci Engng. Sect A: Electr Power Inf Systs 2:187-193

Boersma J, Lee SW (1977) Exact solution for diffraction of a line-source field by a half plane. J Math Phys 18:321-328

Boersma J (1978) Note on an integral equation of viscous flow theory. J Engng Math 12:237-243

Boersma J (1978) On certain multiple integrals occurring in a waveguide scattering problem. SIAM J Math Anal 9:377-393

Belevitch V, Boersma $\mathbf{J}(1979)$ Bessel ratio $\mathrm{K}_{v+1}(z) / \mathrm{K}_{v}(z)$ as a passive impedance. Philips J Res 34:163-173

Lee SW, Boersma J, Law CL, Deschamps GA (1980) Singularity in Green-function and its numerical evaluation. IEEE Trans Antennas Propag 28:311-317

Boersma J, Rahmat-Samii Y (1980) Comparison of two leading uniform theories of edge-diffraction with the exact uniform asymptotic solution. Radio Sci 15:1179-1194

Boersma J (1981) Note on Green's function for a semicircular plate. Int J Solids Structs 17:541-542

Belevitch V, Boersma J (1982) On Stieltjes integral transforms involving $\Gamma$-functions. Math Comput 38:223-226

Belevitch V, Boersma J (1983) Some electrical problems for a torus. Philips J Res 38:79-137

Wiegel FW, Boersma J (1983) The Green function for the half-plane barrier-Derivation from polymer entanglement probabilities. Physica A: Stat Mech Applics 122:325-333

Boersma J, Wiegel FW (1983) Asymptotic expansions for a remarkable class of random walks. Physica A 122:334344

Glasser ML, Boersma J (1983) Exchange energy of an electron gas of arbitrary dimensionality. SIAM J Appl Math 43:535-545

Boersma J, de Doelder PJ, Jansen JKM (1983) A volume problem. SIAM Rev 25:102-106

Ciarkowski A, Boersma J, Mittra R (1984) Plane-wave diffraction by a wedge-A spectral domain approach. IEEE Trans Antennas Propag 32:20-29 
Deschamps GA, Boersma J, Lee SW (1984) Three-dimensional half-plane diffraction—Exact solution and testing of uniform theories IEEE Trans Antennas Propag 32:264-271

Boersma J, Indenkleef JJE, Kuiken HK (1984) A diffusion problem in semiconductor technology. J Engng Math 18:315-333

Boersma J, Nijborg R (1984) Some electrostatic problems for a spindle. Philips J Res 39:121-142

Boersma J, Kaper HG, Kwong MK (1984) Interlacing property of eigenvalues of Sturm-Liouville boundary value problems. In: Kaper HG, Zehl A (Eds), Procs 1984 Workshop Spectr Theory Sturm-Liouville Diff Operators. Report ANL-84-73, Argonne Il: Argonne Nat'1 Lab, pp 57-69

Van Duin CA, Boersma J, Sluijter FW (1986) TM-modes in a planar optical waveguide with a graded index of the symmetrical Epstein type. Wave Motion 8:175-190

Boersma J (1988) The entropy of a Poisson distribution. SIAM Rev 30:314-317

Boersma J (1989) Note on the lifting-surface problem for a circular wing in incompressible-flow. QJMAM 42: $55-64$

Boersma J (1990) The rediscovery of Susan N. Brown's integral. Amer Math Monthly 97:537-540

Belevitch V, Boersma J (1990) Theory of a thin conducting strip with an overhead return wire. Philips J Res 44:541-582

Boersma J (1991) Singularity exponents for complementary sectors. Electr Letts 27:1484-1485

Boersma J (1991) Uniform asymptotics of a Bessel-function series occurring in a transmission-line problem. J Comput Appl Math 37:143-159

Boersma J, Glasser ML (1991) Asymptotic expansion of a class of Fermi-Dirac integrals. SIAM J Math Anal 22:810-820

Boersma J, De Doelder PJ (1991) Two integrals arising from a cloud model. SIAM Rev 33:474-477

Blume S, Boersma J (1992) Diffraction by an elliptic cone and the solution of the wedge diffraction problem. Archiv Elektrotechnik 75:403-409

Boersma J, Dempsey JP (1992) On the numerical evaluation of Legendre's chi-function. Math Comput 59:157-163 Boersma J, De Doelder PJ (1992) A finite part integral. SIAM Rev 34:656-658

Ahluwalia DS, Lewis RM, Boersma J (1992) Uniform asymptotic theory of diffraction by a plane screen. In: Oughstun (Ed), Selected papers on scalar wave diffraction (SPIE Milestone Series, 51). Bellingham WA, USA: SPIE Optical Engng Press. pp 287-305

Lewis RM, Boersma J (1992) Uniform asymptotic theory of edge diffraction. In: Oughstun (Ed), Selected papers on scalar wave diffraction (SPIE Milestone Series, 51). Bellingham WA, USA: SPIE Optical Engng Press. pp 306-320

Boersma J, Danicki E (1993) On the solution of an integral equation arising in potential problems for circular and elliptic disks. SIAM J Appl Math 53:931-941

Boersma J, de Doelder PJ (1993) On alternating multiple sums. SIAM Rev 35:497-500

Boersma J, de Doelder PJ (1994) Two integrals arising from a reaction-diffusion problem. SIAM Rev 36:498-499

Heyman E, Tijhuis, AG, Boersma J (1995) Spherical and collimated pulsed fields in conducting modes. In: Proc 1995 Int URSI Symp Electromagn Theory (St Petersburg, Russia, May 23-26, 1995) pp 572-574

Boersma J, Molenaar J (1995) Geometry of the shoulder of a packaging machine. SIAM Rev 37:406-422

Boersma J (1995) A nonharmonic trigonometric series. SIAM Rev 37:443-445

Boersma J, Glasser ML (1995) A definite integral. SIAM Rev 37:615-618

Boersma J, Anthonissen MJH (1996) Calculations in Mathematics on low-frequency diffraction by a circular disk. Appl Comp Electromagn Soc J 11:47-56

Boersma J (1996) Extinction transport. SIAM Rev 38:152-153

Boersma J (1996) Two combinatorial identities. SIAM Rev 38:152-153

Boersma J (1996) A function arising in one-dimensional percolation. SIAM Rev 38:671-675

Boersma J (1998) Solution to a problem of B. Anicin, involving Bessel functions and elliptic integrals. Orth Polyn Spec Functions Newsletter 8(2):18-19

Boersma J (1998) A sum over binary sequences. SIAM Rev 40:372-374 
Boersma J (1998) A parametric integral arising from a mixed boundary value problem for the Laplacian. SIAM Rev 40:984-986

Boersma J, Yakubovich SB (1998) The asymptotic sum of a Kapteyn series. SIAM Rev 40:986-990

Boersma J, Wood DH (1999) On the self-induced motion of a helical vortex. J Fluid Mech 384:263-280

Glasser ML, Boersma J (1999) A class of integrals associated with the Bethe ansatz. J Phys A-Math Gen 32:82618264 and 33:2457

Glasser ML, Boersma J (2000) Exact values for the cubic lattice Green functions. J Phys A-Math Gen 33:50175023

Wood DH, Boersma J (2001) On the motion of multiple helical vortices. J Fluid Mech 447:149-171

Boersma J, de Hoop AT (2003) Passie voor precisie: In memoriam Christoffel Jacob Bouwkamp (1915-2003). Nieuw Archief voor Wiskunde 5/4:205-207 (In Dutch)

Boersma J, Glasser ML (2005) A differentiation formula for spherical Bessel functions. J Phys A—Math Gen 38:1687-1690

Borwein JM, Zucker IJ, Boersma J (2008) The evaluation of character Euler double sums. To appear in Ramanujan J

\section{References}

1. van Duin CA (1981) On the propagation and ducting of waves in inhomogeneous media. Doctoral thesis, Eindhoven University of Technology

2. Dunford N, Schwartz JT (1963) Linear operators, Part II. Interscience, New York

3. van Duin CA, Boersma J, Sluijter FW (1986) TM-modes in a planar optical waveguide with a graded index of the symmetric Epstein type. Wave motion 8:175-190

4. Wood DH, Guang H (1997) Problem 97-18*. The asymptotic sum of a Kapteyn series. SIAM Rev 39:761-762

5. Boersma J, Yakubovich SB (1997) Solution to Problem 97-18*. SIAM Rev 40:986-990

6. Boersma J, Wood DH (1999) On the self-induced motion of a helical vortex. J Fluid Mech 384:263-280

7. Wood DH, Boersma J (2001) On the motion of multiple helical vortices. J Fluid Mech 447:149-171

8. Batchelor GK (1967) An introduction to fluid dynamics. Cambridge University Press

9. Okulov VL, Sorensen JN (2007) Stability of helical tip vortices in a rotor far wake. J Fluid Mech 576:1-25

10. Bornemann F, Laurie D, Wagon S, Waldvogel J (2004) The SIAM 100-digit challenge: a study in high-accuracy numerical computing. SIAM, Philadelphia

11. Bornemann F (2005) http://www-m3.ma.tum.de/m3old/bornemann/challengebook/Chapter9/MeijerG.pdf

12. Laurie D (2005) Uitdagings in numeriese wiskunde (In Afrikaans. English: Challenges in numerical mathematics). Nieuw Archief voor Wiskunde 5/6(2):142-147

13. Boersma J, Molenaar J (1995) Geometry of the shoulder of a packaging machine. SIAM Rev 37:406-422

14. Boersma J (1962) On a function, which is a special case of Meijer's $G$-function. Compos Math 15:34-63

15. Bouwkamp CJ (1970) Theoretical and numerical treatment of diffraction through a circular aperture. IEEE Trans Anten Propag 18:152-176

16. Bouwkamp CJ (1954) Diffraction theory. Rep Prog Phys 17:35-100

17. Boersma J, de Hoop AT (2003) Passie voor precisie. Nieuw Arch Wiskunde 5/4(3):205-207 (In Dutch. English transl: Passion for precision)

18. Boersma J (1964) Boundary value problems in diffraction theory and lifting surface theory. Doctoral dissertation. University of Groningen, P. Noordhoff Publishers

19. Boersma J (1964) Boundary value problems in diffraction theory and lifting surface theory. Compos Math 16:205-903

20. Boersma J (1967) Buiging, een spel van licht en schaduw. (In Dutch) Inaugural speech. Eindhoven University of Technology (English: Diffraction, an interplay of light and shadow)

21. Boersma J, Glasser ML (2005) A differentiation formula for spherical Bessel functions. J Phys A: Math Gen 38:1687-1690

22. Borwein JM, Zucker IJ, Boersma J (2008) The evaluation of character Euler double sums. Ramanujan J (to appear)

23. Hardy GH (1940) Ramanujan. Twelve lectures on subjects suggested by his life and work. Cambridge. Third (corrected) edition (1978) Chelsea Publ Co, New York

24. http://www.users.cs.dal.ca/ jborwein/bzb7.pdf

25. Boersma J (1960) Computation of Fresnel integrals. Math Comput 14(72):380

26. Boersma J (1960) On a numerical method for the computation of Fresnel integrals. Rept TW-2, Mathematisch Instituut, Rijksuniversiteit Groningen

27. Bleistein N, Handelsman RA (1975) Asymptotic expansion of integrals. Holt, Rinehart and Winston, New York 